\title{
The Problems and the Development of Exploration of China's Emergency Management System
}

\author{
Lutao Tian \\ Jinan University, Guangzhou, China \\ Email: 1171520470@qq.com
}

How to cite this paper: Tian, L.T. (2018) The Problems and the Development of Exploration of China's Emergency Management System. Open Journal of Social Sciences, 6, 165-182. https://doi.org/10.4236/jss.2018.612015

Received: November 28, 2018

Accepted: December 25, 2018

Published: December 28, 2018

Copyright $\odot 2018$ by author and Scientific Research Publishing Inc. This work is licensed under the Creative Commons Attribution International License (CC BY 4.0).

http://creativecommons.org/licenses/by/4.0/

\section{c) (i) Open Access}

\begin{abstract}
In recent years, with the rapid development of China's economy, the natural ecological environment has also been damaged. The disasters occur frequently, such as the Wenchuan Earthquake, the Southern Snowstorm and the Mangrove Typhoon, the stampede in Shanghai and the explosion in Tianjin. In this situation, we have to face the problem and deal with the variety of emergencies, because it would make people suffer enormous loss of life and property. Compared with the developed countries in the West, China's emergency management system started late and the development is not enough. Therefore, our country must take action to construct an emergency management system to guarantee the safety of the development of economy, society and the people in the future. This paper first makes a brief analysis of the current situation and development of China's emergency management system, and finally puts forward some reasonable suggestions.
\end{abstract}

\section{Keywords}

Public Crisis, Emergency Management System

\section{Introduction}

In recent years, various types of crisis incidents have occurred frequently, causing great harm to the society and seriously threatening the lives and property of the people. Taking the above-mentioned overseas beach incident as an example, it has brought us warnings: public crises and emergencies have become important hidden dangers in building a socialist harmonious society and sustainable development in China. We must attach great importance to emergency management. 
Public crisis refers to emergencies that may be jeopardized by public safety, normal security, and normal order due to natural disasters, social security incidents, or social operating mechanisms. These public crises have affected the development of society and the safety of people's lives and property, causing huge losses to China's economy and society. Hong Yi, a member of the Standing Committee of the National People's Congress and the president of the China Emergency Management Association, believes that emergency management should pay attention not only to existing work innovation, but also to make long-term planning, build a comprehensive public safety net, and focus on four comprehensive strategies. We should firmly grasp the overall requirements for improving the modernization of the national governance system and governance capacity. At the same time, we should also firmly establish five development concepts of "innovation, coordination, green, openness and sharing" to promote the construction of national public security system [1]. Therefore, in order to reduce the occurrence of various public crisis events and reduce the damage caused by the crisis, we must commit ourselves to the construction of an emergency management system, build a comprehensive public safety network, further strengthen and improve the related system construction, and ensure the people safety, including the safety of life and property of the masses and the long-term stability of society.

This paper only makes some simple analyses in the current situation and the development of China's emergency management system, and tries to put forward some suggestions for the future direction of China's emergency management.

\section{Research Objects and Research Significance}

\subsection{Concept Definition}

At present, it is no unified standard for public crisis and emergency management in the academic community. The term crisis was originally derived from Greece, which is widely used in the medical field and is a medical term. In the field of public administration, domestic and foreign scholars have different definitions of the concept of "public crisis". Rosenthal and others in the Netherlands believe that crisis is a serious threat to the basic value of a social system and the framework of the code of conduct, and in the case of extremely high time pressure and uncertainty, it must make critical decisions [2]. William, a well-known emergency management scientist at the State University of Georgia in the United States, believes that "emergency management is the management of risks so that society can coexist with environmental or technological hazards and respond to disasters caused by environmental and technological hazards [3]". Sun Benchu, the Taiwanese scholar, believes that: "Crisis refers to an organization that has immediate and serious threats to the survival of the organization caused by internal and external environmental factors" [4]. Xue Lan and others believe that in the crisis scenario, sudden emergencies and uncertain prospects create a high degree of tension and pressure. In order for the organization to survive in 
the crisis and minimize the damage caused by the crisis, policy makers must make critical decisions and response to the crisis in limited time. In my view, the public crisis is a sudden emergency or an abnormal social situation. It refers to social life and people caused by force majeure or sudden major natural disaster events, accident disasters and social security incidents. An emergency in which property safety poses a serious hazard. Emergency management is an emergency management system established by the government or other public organizations through the integration of various social resources, coordination of various social forces, and application of advanced science and technology to ensure the society harmony and stability and safety of people's lives and property.

According to the development cycle of public crisis, the public crisis management process can be generally divided into crisis early warning and preparation, crisis identification, crisis isolation, management crisis and recovery. The five stages have their own different roles and characteristics, which are indispensable and interconnected, which together constitute the general process of crisis management in China.

1) Crisis warning and preparation

Crisis warning and preparation mainly refers to people's cognition of the crisis, which is characterized by a strong sense of crisis and an early warning system built on the basis of cognition. Crisis warning is the first step in crisis circle and the key to crisis management. It is a sense of crisis, though the crisis often occurs in the form of an emergency, the probability of occurrence is very low, but the emergency is an objective existence. In this sense, the crisis is inevitable. Therefore, it is necessary to pay attention to the crisis from the ideological point of view. Before the accident, there will always be some signs, as long as these signals are captured in time. By analyzing and processing in time and with effective measures, we can minimize the losses caused by the crisis and even avoid the crisis.

2) Identify the crisis

It is the basis of public crisis management. It refers to the emergence and the development of public crises in the future based on past and present data, intelligence and materials related to emergencies in a region, using logical reasoning and scientific prediction techniques to make reasonable judgments and predicates, and then guide people to plan and carry out a series of effective activities for public crisis prevention. Identify the crisis and identify the possible crisis, such as the type, level, scope etc.

3) Isolation crisis

Isolation crisis refers to the stage that controls the source of crisis and cuts off the spread of the crisis. Since the crisis has a knock-on effect, a crisis is not properly handled, and it often triggers another crisis. Therefore, when a crisis occurs, we should take prompt measures to cut off the spread of the crisis and timely release the crisis that has already erupted. Isolation is to prevent the spread of the crisis. In addition, the crisis often occurs in a small area, so the first step in crisis management is to isolate the crisis in order to control the crisis 
spread to other areas and cause greater losses. Segregation crisis must start from two aspects: segregation of people and isolation of accidents.

4) Management crisis

In Western textbooks, management crisis is often referred to crisis communication management. The reason is that strengthening information disclosure and public communication, and seeking public understanding and support are the basic countermeasures in crisis management. Crisis management refers to the process of planning, decision-making, dynamic adjustment, and mitigation of crises in response to various crisis situations. Its purpose is to eliminate or reduce the threats and losses caused by the crisis, in order to respond to sudden crisis events and resist sudden disaster events. Crisis management includes several basic elements:

a) Equipped with professional crisis management talents. Only with professional management personnel, comprehensive and in-depth research on the crisis, and the development of strict pre-control measures and response plans, can implement effective crisis management.

b) Adopt advanced crisis prediction methods and measures. The development or introduction of advanced crisis prediction methods to improve the scientific and technological content of crisis prediction are necessary for modern crisis management.

c) Eliminate and deal with crises in a timely and effective manner. It is important to improve the ability to respond to the crisis and the speed of response, and to minimize the damage caused by the crisis.

5) Recovery

The work of the aftermath of the crisis is mainly to eliminate the remaining problems and impacts after the crisis. It should start from the following aspects: First, the rescue of personnel after the crisis, the first task is to rescue and appease the people; Second, the crisis assessment. A comprehensive evaluation of the crisis management work, including the evaluation of the organization and working procedures of the early warning system, the crisis management plan, and the crisis decision-making, should detail the various problems in the crisis management. And then, guide public opinion. Making the crisis extend benign, which requires to discover opportunities to make the crisis turn to the direction that is beneficial to us. Finally, the crisis analyzes and summarize. It can avoid repeating the same mistakes, and sum up experience.

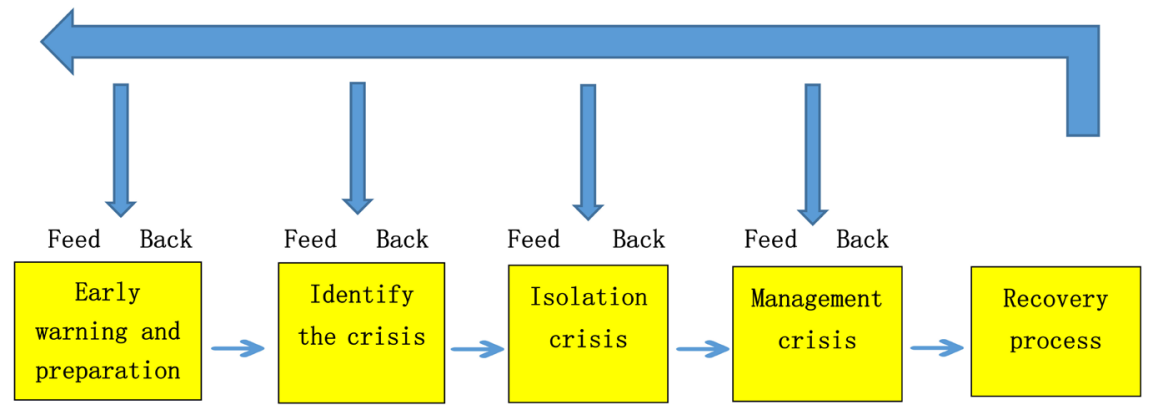




\subsection{Analysis of the Characteristics of the Research Object}

1) Sudden and urgent

Public crises are generally sudden emergencies. They are gradually developed from a series of small things. However, due to the unpredictability of the time and the place, people may not have any perception or preparation beforehand. In the face of a sudden crisis, it may cause great harm [5]. A crisis event may have a series of small incidents gradually developed, but we cannot foresee the actual time and where occur. When a crisis event reaches a critical pressure, it will suddenly erupt. This is beyond our control. Therefore, policy makers are required. A satisfactory crisis management plan must be implemented under limited information, resources and time to make quick decisions and effective actions.

2) A strong social influence

After the general crisis, it will bring great harm, pose a serious threat to the basic value of the social system, the framework of the code of conduct, and cause widespread concern in the society, which may cause panic in the whole society and interrupt the normal order and operation of the society. The mechanism brings great trauma to the psychology of the public. At this time, we must try our best to appease the physical and psychological trauma of the public and avoid causing worse results.

3) High degree of uncertainty

With the development of the crisis, there are many uncertainties when the crisis occurs. It is impossible for us to know when crisis would occur and it is even impossible to know whether the next step of the crisis will continue to deteriorate. Everything seems to change rapidly, and it may cause a series of chain reactions. The time, shape, nature power and the process of crisis cannot be judged routinely. The consequences and impacts of the crisis events are not available for reference. All we can do is learn to protect ourselves and stay calm in a highly uncertain crisis condition, and minimize losses to the greatest extent possible.

4) Uncertainty in decision making

When the crisis occurred, it was urgent and sudden. At this time, no matter whether the government or other public departments can handle the problem in a conventional way, the decision turned into non-procedural decision-making. Although information and resources are limited, but decision makers must quickly find a reasonable response plan in short time. From normal to emergency, from normal to abnormal, the relevant departments or the first responder can be authorized in advance, so as to avoid the unclear decision-making identity, unclear responsibility when the crisis happened and the abuse of power.

\subsection{Research Significance}

China is in a social high-risk period that social transformation, system transition, risks and opportunities coexist [6]. Today, there are many various natural 
disasters occurrence and man-made security incidents, such as, finance, information, natural disasters, and social security incidents have gradually common in the rapid development of society. It has already threatened the stability of our country and the people's normal life. Facing these crises, it is necessary for us to make corresponding explorations and researches in order to find some effective measures to reduce such incidents happen.

Improving emergency management system, the ability to prevent and deal with public crisis is a major event that affects the overall economic and social development of the country, including the safety of people's lives and property. It is an important part of building a socialist harmonious society, which adhere to the human-oriented principle and governance for the people. It is an important aspect of performing government functions and further improving administrative capacity. By strengthening crisis management, establishing and improving social early warning mechanisms, emergency public emergency response mechanisms and social mobilization mechanisms, which can prevent and reduce public crises and damages, protect lives and property of the public, prevent national security and social stability and promote comprehensive, coordinated and sustainable economic and social development.

With the promulgation of the "National Emergency Response Plan for Public Emergencies" issued by the State Council on January 8, 2006, China's emergency response framework system was initially formed [7]. Emergency management has begun to develop in China and has gradually played an important role [8]. It also plays an important role in the government's public policy agenda. The strategic response to the public crisis has been raised to the height of the country. The construction and improvement of the emergency management system is conducive to strengthen the governance capacity of the Chinese government and reduce disaster risks, which is benefit for public to survive and develop in a healthy and safe environment.

This paper studies the problems and development exploration of China's emergency management system, summarizes the shortcomings still existing in China's emergency management work, and provides some suggestions for the government to continuously improve emergency management and make scientific decisions. At the same time, it also put forward some suggestions for the future development direction of China's emergency management.

\subsection{Limitations of Research}

1) This paper is to study the emergency management in China. Because my academic level is limited and the research time is not long, the representativeness of the selected cases may be insufficient, and the content of the selected cases will be defective and the information collection will be flawed.

2) Emergency management system is a hot issue in the field of emergency management research. This article is an exploratory attempt and there are some shortcomings. Due to the limited academic research ability of individuals, there 
will inevitably be many confusions and difficulties in the process of research and development. The depth and breadth of thinking will inevitably have loopholes and defects. This research needs to be further improved.

\section{Current Situation and Existing Problems of China's Emergency Management System}

\subsection{Development History and Current Situation of China's Emergency Management System}

The development of emergency management in China has mainly gone through three processes. The first stage is the budding period. China's emergency management system was still very simple before 2003. The research work mainly focused on disaster management, but lacked experience in comprehensive crisis management [9]. The second stage is the period of rapid development. After the SARS incident happened in 2003, many problems were exposed in our government emergency management. The series of problems prompted the government to reconstruct emergency management system. President Hu Jintao clearly pointed out the problems and shortcomings in China's emergency management at the National Conference on SARS Prevention and Stress, and emphasized the ability to greatly enhance the response to risks and emergencies. At the same time, Premier Wen Jiabao proposed "to strive for three years to establish and improve emergency response mechanisms for public health emergencies and improve public health emergency response capabilities." In October 2013, the "Decision of the Central Committee of the Communist Party of China on Several Issues Concerning the Improvement of the Socialist Market Economic System" adopted by the Third Plenary Session of the 16th CPC Central Committee emphasized that it is necessary to establish and improve various early warning and emergency mechanisms to improve the government's ability to response to emergencies and risks. Since then, China's emergency management has begun to develop rapidly. The third stage is the period of quality improvement. 2008 is a special year for our country. During this year, many crisis events such as the Southern Snowstorm, the Wenchuan Earthquake and the Lhasa Incident occurred. The big test, for this reason, former President $\mathrm{Hu}$ Jintao pointed out at the National Earthquake Relief Commendation Conference: "We must further strengthen emergency management capacity building." China's emergency management construction once again stood at a new starting point in history, and the quality has been improved. Especially, the construction of China's emergency management system started relatively late, so the development time is short. We can know that the system is not perfect, and it is particularly inadequate in the comprehensive disaster emergency management system. There is no corresponding supporting system and operational mechanism, and no corresponding competent department is established. After the crisis incident, the decision-making identity is not clear enough, the power and responsibilities are relatively vague, the departments lack communication, which cannot form a unified 
team. If government departments lack of crisis awareness, the emergency response at the scene is unreasonable. The public's crisis awareness and self-protection ability are weak. Once a crisis happened, administrators will abuse their power to seek private interests, contributing to serious social impacts and inadequate laws and regulations. In short, China's emergency management system still has tremendous room for improvement. In the future, it is necessary to increase investment in this area and strive to develop and improve China's emergency management system at an early date.

\subsection{Problems in China's Emergency Management System}

1) Lack of awareness

Judging from the various public crisis events that have occurred in China in recent years, the crisis awareness and prevention awareness of our government and citizens are still relatively lacking. In many crises, the best rescue time has been missed, resulting in the loss of many lives. For example, on the morning of October 1, 2015, a rear-end collision occurred at the Yongtaiwen Expressway. The rescue time was delayed due to the occupation of the emergency passage by individual vehicles, which eventually led to the death of one person. We must strengthen the awareness of crisis prevention by our government and citizens, start from the roots, and raise the awareness of crisis prevention among our citizens.

2) The warning and monitoring system are not perfect

There are still many problems and deficiencies in the public crisis early warning and monitoring system in China. Many local early warning facilities are not in place and imperfect, which brings certain difficulties to the rescue work in the disaster. On the other hand, the development of emergency management in China started relatively late. The technology in this area is still backward, and there is no advanced warning and monitoring system, which brings certain difficulties to the emergency management work. For example, the emergency management of heavy polluted weather still has a series of problems such as inaccurate positioning of the plan, insufficient connection of the plan, lag of the warning release, and “one size fits all” response measures. It is difficult to really play an emergency role.

3) The linkage mechanism of emergency management is imperfect

China's emergency management department is still relatively complete in the vertical system, but various departments are lack of communication and the efficiency of emergency management is low. The main reason is that organizational departments do not have a unified command mechanism. Therefore, establishing the necessary linkage coordination mechanism is of great significance for emergency management.

4) The social participation mechanism is not perfect

Judging from the current situation of emergency management in China, public generally lack crisis awareness and self-rescue skills. After the crisis, the citi- 
zen participation is not active, and the whole society pays insufficient attention to the prevention of risks. The social participation mechanism is a very important part of emergency management, and we need to do much work in this area [10].

5) Emergency publicity and education are not in place

Emergency publicity and education are important means to ensure the implementation of emergency plans when the crisis happened. It is also an important way to improve the ability of accident prevention. However, there are many problems in emergency rescue education and training at present. First, governments at all levels and relevant departments have not recognized the development of emergency rescue publicity and education, and the focus is not enough. There is no effective form of publicity and education activities to attract public learning; second, the safety awareness of employees is weak, lack of self-help skills, mutual rescue knowledge, on-site escape ability, and safety protection equipment is incomplete. The "three violations" phenomenon is serious, resulting in a large number of hidden dangers and accidents. Third, the emergency command and government management staff at all levels, relevant departments and enterprises lack of professional corporation skills, poor on-site disposal capabilities, and little practical experience, which restrict the effectiveness of emergency rescue work.

\subsection{The Advantages of Developed Countries in the Emergency Management System and the Places Worthy Learning}

In developed countries such as the United States, Japan, Australia and Canada, a well-established and targeted emergency management system and successful practices have been established, and an emergency system and mechanism with distinct characteristics have been formed. Their theories and practices are worthy of learning.

1) Emphasis on education

As a country with earthquakes frequently, Japan rarely suffers casualties in the earthquake. In contrast, the losses caused by the Wenchuan earthquake in China are too more. The difference between the two countries is obvious because special attention focus on earthquake knowledge. Simulated earthquake experiences are carried out regularly, so that children can master critical self-rescue skills at an early age. On the contrary, children in China are lack of knowledge in this filed.

2) Emphasis on the construction of corresponding organizational departments and the cultivation of professional talents

In 1979, the United States established the Federal Emergency Management Agency, which was responsible for emergency management throughout the country. Later, the National Emergency Training Center and other related departments were established. Many undergraduate and postgraduate majors about emergency management were established in many universities across the country. A large number of professional talents were cultivated. In contrast, 
China's construction falls behind a lot in this area. There are no independent departments and agencies focus on emergency management. Most of them are temporary that set up after the disaster. There are only a few disciplines. The university has few undergraduate and postgraduate majors in emergency management and lacks corresponding professional talents.

3) Established a mature emergency management system and case base

Western developed countries have rich experience in emergency management. They have established a mature system and case base. After a crisis event, they can find matching cases or plans from the base immediately, greatly reducing time in decision-making. The procedural process can win more precious time to rescue in disaster. This is exactly what lacks in China emergency management, so we should learn from the corresponding theoretical knowledge for our use.

\section{Establish and Improve a Mature Emergency Management System}

Xie Zhenchang, head of the emergency management expert group, believes that the development of emergency management must continuously strengthen emergency management from the height of modernizing the national governance system and governance abilities. The first is to build a public security emergency management system based on people, disasters, process, and the whole society. The second is to update concepts and practice, and promote emergency management from focusing on emergencies to focusing on public security risk management, from the national disaster relief to the national defense. The third is to strengthen the coordination of policies, talents, science and technology, industry, improving the level of public safety management and emergency management. The fourth is to strengthen the legal system. The fifth is closely related to the country's major strategy and weak link to deepen national security and emergency management. Gong Weibin, director of the Emergency Management Training Center of the National School of Administration, believes that it is necessary to promote the discipline construction of emergency management. At present, the development of China's emergency management discipline has the following characteristics. First, risk social accident disasters have promoted the development of emergency management disciplines. Second, the government's emphasis has provided guarantees for the development of emergency management disciplines. Third, typical case learning is an important way and mean [11].

China's emergency management system can be built from the following aspects:

1) Strengthening prevention at quiet time

Born in sorrow and sorrow, the ancients know the truth. We should understand that preparations should be done in peacetime, enhance the sense of urgency, be prepared for danger in times of peace, take precautions, pay attention to public safety, and be prepared for public emergencies. Pre-planning prepara- 
tion, organization preparation, and material preparation, etc., establish a comprehensive prevention mechanism, do not fight unprepared, combine prevention and emergency management, and do pre-prevention work for public crisis events.

2) People-oriented and reduce losses

Taking the protection of the lives and property of the people is the most important task, taking people as the foundation, thoroughly implementing the scientific development concept, and regard people as the most important factor. Before any public crisis happened that may cause casualties, people should be shifted in time. After the crisis, we should priority to take the measures to rescue life, and at the same time do the protection of rescue workers to minimize the casualties caused by the crisis.

3) Rapid response and unified leadership

Time is money, time is life. The efficiency of this organization determines response. After the crisis, what we have to do is to clear the leadership responsibility and decision-making identity, quickly set up a working team, and join into rescue work. Launching a unified command system, quickly formulate corresponding rescue plans and implement plans, strengthen the construction of emergency response teams based on territorial management, fully mobilize the role of townships, communities, enterprises, institutions, social groups and volunteer teams, relying on the masses to establish a mature and rapid response mechanism, obtaining sufficient and accurate information in a timely manner to track, judge and make decisive decisions, which can minimize hazards and impacts, avoid unreasonable multi-level leadership and staff deployment.

4) Responsible for grade and coordinated coordination

We need to establish a system that combines hierarchical response and territorial management. The central and local governments communicate with each other. The central unified coordination and command and the local organizations take concrete actions, but they coordinate with each other, establish a linkage coordination mechanism, and play different role in each department for crisis. What should do is to establish and improve the linkage coordination system, implement the unified urban police, hierarchical classification and disposal work system, strengthen communication and coordination between departments, regions, military, local and central dispatched units to local governments, etc. It is necessary to pay attention to communication, learn from each other's experiences, and carry out close cooperation to avoid the situation of water management and individual administration in Kowloon, and to establish an emergency management system with unified command, rapid response, close connection, and coordination and efficiency. According to the seriousness, controllability, resources needed, and scope of influence of public emergencies, the corresponding plans are initiated.

5) Integrating resources and making the best use of them

Resources are an important factor. No matter what we do, resources are indispensable. In the face of crisis events, we must integrate each organization and 
the potential of each staff resources to make the best use of it. Integrating the most effective and extensive resources for us to integrate, monitor, forecast, and alert information systems for public emergencies, establish network interconnection, information sharing, and scientific and effective prevention systems. Integrating existing public emergencies command and organization network is to establish a unified, scientific and efficient command system; Integrating the existing emergency response resources for public emergencies to build a safeguard system with clear division of labor, responsibility implementation, and standing and unremitting. Do everything that is possible to use human, material and financial resources to improve the relevant institutional system, so that our people can live in a safe and stable environment, no worrying about the occurrence and response of crisis events.

6) Relying on science and improving quality

Science and technology are the primary productive forces. The 21st century is the era of science and technology and the era of talents. Only through scientific analysis and argumentation can we establish an excellent emergency management organization and establish an efficient emergency management system. At the same time, cultivating professional talents are also very important. People are the most important part of all factors. It is meaningless except for people to talk about the system. Each of us must start from improving our own quality, receive education, and learn the corresponding emergency. Management and crisis assistance knowledge are, in the event of a disaster, the first to learn how to save themselves. Rescue workers should also regularly participate in training and simulation exercises, in order to quickly joined into rescue work after the crisis.

\section{Taking Measures to Construct China's Emergency System}

\subsection{Implementing the Spirit of Country Documents and Raising Awareness}

Safety production emergency management is an important part of safe production. Comprehensively do a good job in emergency management of safety production, improve the ability of accident prevention and emergency response, avoid and reduce casualties and losses caused by accidents as much as possible. It is an inevitable requirement of adhering to the people-oriented principle, implementing the scientific development concept, and safeguarding the fundamental interests of the people. We must conscientiously implement the "Opinions of the State Council on Comprehensively Strengthening Emergency Management", the "General Emergency Response Plan for Public Emergencies" and the requirements of the "Eleventh Five-Year Plan" for national economic and social development, and adhere to unified planning and territoriality. The principle of grading and responsibility is carried out under the leadership of the local government to speed up the construction of a production safety emergency rescue system.

First, basing on a local reality is necessary in accordance with the principle of 
combining blocks and blocks, and formulate a complete set of government emergency plan system to ensure the requirements of emergency rescue work. It is necessary to clarify the respective duties and tasks of various government departments in accident emergency rescue. In the event of an accident, the relevant departments and units must act in accordance with the division of responsibilities and immediately take action, and perform their duties and work together to ensure that the emergency rescue work has achieved the desired results.

The second is to establish and improve the emergency rescue mechanism of "unified command, responsive, coordinated and efficient operation". It is necessary to incorporate the construction of emergency rescue system into the government safety assessment system, through improving the importance of emergency rescue work at all levels of government by establishing an accountability system for assessment. Promoting the construction of emergency systems at the provincial, municipal and county levels and establishing a system as soon as possible are necessary. Besides, it need to identity responsibilities, streamlined emergency rescue system and "five implementations" of organization, preparation, responsibilities, staff and funds.

The third is to conduct in-depth investigation and research. Finding out the existing resources of various emergency rescue teams and equipment, establish a provincial and municipal emergency resource database as soon as possible, comprehensively grasp emergency resources, and actively promote the integration of emergency rescue teams, equipment, materials and other resources. Sharing information form a system of unified command, mutual support, close coordination, and coordinated response to accident disasters; speeding up the establishment of three-level network information systems for emergency rescue provinces, cities, and counties, and comprehensively using computer technology, network technology, and communication technology is to establish a connection province. The city, county and county safety production emergency rescue command center and rescue team's two-way information transmission network, and connected with the national private network; Classification and formation of accident emergency rescue experts, organize experts to participate in accident rescue, guidance, assist in accident rescue. The on-site command department formulated the rescue plan and did a good work in the rescue organization, making the rescue work scientific, orderly and powerful.

\subsection{Improving Emergency Plans and Strengthening Emergency Rescue Drills}

According to the requirements, the production and operation units of high-risk industries should organize at least one-time emergency simulation drill for the emergency plan every year. The production and operation units of other industries shall regularly organize emergency plan drills. In order to standardize the emergency plan and improve the efficiency of emergency rescue, the government needs to strengthen the guidance, the training and timely exchange the experience of the preparation of the plan; secondly, combine the actual situation 
of local safety production, the characteristics of the production process and potential risks of the enterprise. The distribution, the emergency drill work plan, and the supervision, inspection and guidance of the emergency rescue drill work shall be strengthened in accordance with the principle of "emphasizing key points and paying attention to actual results". It is necessary to further standardize the emergency drill work, regularly organize various forms of emergency plan drills such as desktop deductions and actual combat simulation exercises, sum up the experience and lessons of the drills in a timely manner, and urge relevant departments and enterprises to timely revise the plan in response to existing problems.

About drills, on the one hand, the relevant personnel should understand the emergency rescue system, be familiar with the emergency rescue methods, master the use of emergency rescue tools, equipment, and further improve the ability to deal with emergencies and prevent serious accidents. On the other hand, through drills to solve the problems of coordination between the departments within the enterprise and the relevant departments of the local government, the scientific, feasibility, pertinence and correctness of the organization, personnel, equipment and emergency plans for emergency rescue are tested. It also modifies and perfects the existing deficiencies and defects to improve the coordination, rapid response and disposal capacity of emergency rescue, ensure the orderly operation of all aspects of rescue work after the accident, and reduce the accidents caused by blind rescue.

\subsection{Increase Safety Investment, Strengthen the Construction of Emergency Teams, and Improve Emergency Response Capabilities}

First, government should set up special funds as soon as possible from central to local, specifically for: emergency drills for major accidents, provide emergency rescue facilities and equipment for professional rescue teams in the region; and advance funds for accident rescue.

Second, according to the industrial layout, distribution of dangerous sources, traffic and geographical conditions, industries should accelerate the pace of construction of various rescue bases and regional professional backbone rescue teams, focus on strengthening national-level regional rescue bases such as mines and dangerous chemicals, and professional backbone rescue teams.

The third is to promote emergency team business training, increase training and practical drills, organize and guide various emergency rescue teams to carry out preventive safety inspections and potential risks investigations for enterprises within the scope of services, and guide various emergency rescue teams to participate in major hazards of enterprises.

The fourth is to solve the problem of funding for emergency rescue teams. At the national level, national professional rescue teams 'wages and benefits should be fully supplied by the state finances; for the local and part-time rescue teams, the local finances should be supplemented, and the enterprises should mention 
the safety production costs. At the same time, all the special and part-time rescue team members purchase high-value insurance to mitigate rescue workers pressure.

The fifth is to cultivate emergency rescue volunteers and play an important role in social emergency resources. There are few secondary and part-time rescue workers in various types of emergency rescue agencies, and the rescue force is weak. We should learn the experience from some countries such as Australia and New Zealand, where volunteers with certain professional knowledge and skills, as the most important human resources in emergency rescue. The rescue relies on thousands of well-trained volunteers to finish. The government emergency management agency provides rescue equipment for volunteers. In this way, in the event of a crisis, the emergency rescue volunteers can make up for the contradiction between the special and part-time rescue forces, and minimize accidents, injuries and losses.

\subsection{Strengthening the Publicity and Education of Emergency Plans and Emergency Self-Help Mutual Rescue}

The emergency rescue plan is an important means to ensure the implementation of the emergency plan for safety production accidents. Governments at all levels, relevant departments and enterprises should adopt different methods to carry out publicity, education and training on emergency production rescue plans and emergency self-help mutual rescue common sense, so that relevant departments and their staff in emergency plans can raise awareness of crisis and responsibility, and clarify emergency Work procedures to improve emergency response and coordination capabilities. On this basis, ensure that all employees have basic emergency skills, familiar with enterprise emergency plans, master accident prevention measures and emergency procedures, and improve emergency efficiency; When the disaster happen, "time is life", who can take effective self-help and mutual rescue measures in the short time, the opportunity of survival is high. It is necessary to incorporate the propaganda and education of the public into mutual rescue and emergency plan to strengthen the training and education about safety knowledge. It is necessary to broaden the channels of education, innovate the form of education, and strive to promote emergency management into institutions, community, enterprises, schools, and towns. Through a variety of forms can effectively improve the public's awareness of prevention and self-rescue, so that they can master common methods of self-rescue and mutual rescue, and minimize casualties and property losses.

\subsection{Establish and Improve the Public Crisis Management System}

The public crisis management system must be established and improved in accordance with the requirements of integration, and the system should ensure the effective integration of public crisis management resources and improve the mobilization ability of the society to cope with public crises. There are some issues should be solved in the construction of the public crisis management sys- 
tem:

1) Establish a unified command system for public crisis management

The establishment of a unified command system for public crisis management is to meet the needs of public crisis management. Public crisis management involves different departments and different administrative regions. Decentralized departmental management is difficult for children to adapt to emergency management requirements. A unified command system is beneficial to Quickly and efficiently make decisions and mobilize resources, reduce management links, reduce the occurrence of mutual detachment, and facilitate the transformation of individual strength into overall strength, thereby exerting overall effectiveness. Strengthening the unified command and comprehensive coordination of public crisis management is a common practice and development trend of the countries in the contemporary world to improve their ability to cope with the crisis.

2) Establish a hierarchical response and territorial integration system

The establishment of a hierarchical response and a territorial combination system is to adapt to the unpredictability and rapid spread of public crises, and to establish a management system to effectively solve the problem of block and bar. On the one hand, for public crisis management across administrative regions, administrative levels, and departments, higher levels of leadership and coordination agencies are needed to strengthen coordination and unified command. Therefore, it is necessary to establish a hierarchical response system based on the ability to respond to crises. On the other hand, the territorial management system is a basic system that we need to cooperation in dealing with crises and respect the decisions of local governments. Establishing a system of hierarchical response and territorial integration requires a management system in charge of the lead and other departments to cope with the occurrence of public crises.

3) Establish and improve the crisis management linkage coordination system

Establishing and improving the public crisis management linkage coordination system is of great significance for improving the ability to respond to public crises. It provides institutional guarantee for establishing a public crisis management system with unified command, division of labor and cooperation and resource sharing. Establishing a mature crisis management linkage coordination system can strengthen the overall planning, resource integration and overall coordination of inter-departmental and inter-regional crisis management system construction. It is the coordination and mutual support of various resources and forces, avoiding duplication of construction and idle resources.

\section{Conclusions and Outlook}

The occurrence of the stampede on the Bund in Shanghai brought us certain warnings. Public crises and emergencies have become an important potential danger in building a harmonious socialist society and sustainable development 
in China. More and more people from all walks of life have attached great importance to how to effectively respond to emergencies and properly prevent and deal with crises [12]. Since the reform and opening up, China's economy has developed rapidly and various undertakings have flourished. Since the 21 st century, especially since the 13th Five-Year Plan, China's social development has entered a critical stage, which is related to the realization and overall completion of the two hundred-year struggle goals. The goal of a well-off society requires political system reform and economic system reform to be carried out continuously. Reform has gradually joined into deep-water area. Under this special period, various social contradictions have gradually exposed, and the social interest relationship has become complicated. Maintaining social stability and harmony is the most important task at present, and public crisis events are precisely the important factors that influence social security and affect people's lives.

Public crisis management is an indispensable part of public management and an important manifestation of public management. Effective public crisis management is a very complex dynamic management. In the process, we must face the crisis with the attitude of "predicting everything without prejudice and solving it". We should prepare for possible crisis events from the perspective of long-term planning, and build a comprehensive, scientific, reasonable and efficient public crisis management strategy, and constantly cultivate people's awareness of crisis, ability to respond to crisis and psychological quality.

In short, at this critical stage of China's current social development, both the government and the individual must fulfill their responsibilities and obligations, commit themselves to the improvement and construction of China's emergency management system, comprehensively improve the level of China's emergency management, fully guarantee China's economy and society stability, and make our own contribution to the realization of the great rejuvenation of the nation at an early date.

\section{Conflicts of Interest}

The author declares no conflicts of interest regarding the publication of this paper.

\section{References}

[1] Jiang, C.S., Chen, Y. and Li, H.M. (2015) Promoting Emergency Management Practice Exploration and Theoretical Innovation to Accelerate the Construction of an All-Dimensional Three-Dimensional Public Safety Network. Rational Speculation, Academic Frontier.

[2] Luo, J.P. (2011) Public Crisis Management from the Perspective of Governance Theory. Business Times.

[3] George, D. and Gong, J. (2011) Introduction to Emergency Management. Beijing Intellectual Property Publishing House, Beijing.

[4] Sun, B.C. (2001) Public Administration. Taiwan Zhisheng Culture Enterprise Co, 
Ltd.

[5] Niu, X.D. (2013) Discussion on the Crisis Management of Public Relations in the Coal Industry. China Science and Technology Expo.

[6] Xu, M. (2013) Government Crisis Management Innovation in a Risk Society. People's Forum.

[7] Zou, Y. (2008) Research on Emergency Management Mechanism and Countermeasures of Stock Market Emergency.

[8] Li, W. (2013) Subject Integration: Building China's Diversified Social Assistance System. Social Security Research.

[9] Liu, G.F. (2015) A Review of Research on Emergency Management of Water Disaster Events. People's Yellow River.

[10] Lu, W.G., Huang, X.Z. and Tian, T. (2016) Comparative Study on Emergency Management of Large-scale Mass Activities in China and the United States. Journal of the Party School of the Guizhou Provincial Committee of the Communist Party of China.

[11] Jiang, C.S., Chen, Y. and Li, Y.M. (2015) Promoting Emergency Management Practice Exploration and Theoretical Innovation to Accelerate the Construction of an All-Dimensional Three-Dimensional Public Safety Network. Rational Speculation, Academic Frontier.

[12] George, D. and Gong, J. (2011) Introduction to Emergency Management. Intellectual Property Publishing House, Beijing. 